\title{
Can a University Reproductive Medicine Centre Be Financed Under the Pre-Existing General Conditions in Germany?
}

\section{Ist ein universitäres reproduktionsmedizinisches Zentrum unter den gegebenen Rahmenbedingungen in Deutschland finanzierbar?}

\section{(ㄷ) (i) 옹 $\ominus$}

\section{Authors}

Thomas Hildebrandt, Nicola Oversohl, Ralf Dittrich, Laura Lotz, Matthias W. Beckmann, Michael P. Lux

Affiliation

Erlangen University Hospital, Department of Gynecology and Obstetrics, CCC Erlangen EMN, Friedrich Alexander University, Erlangen, Germany

Key words

IVF, ICSI, reproductive medicine, financial resources, continuing education, endocrinology

Schlüsselwörter

IVF, ICSI, Reproduktionsmedizin, finanzielle Ressourcen, Weiterbildung, Endokrinologie

received $\quad 31.7 .2018$

revised 16.9.2018

accepted 24.9.2018

Bibliography

DOI https://doi.org/10.1055/a-0749-9103

Geburtsh Frauenheilk 2019; 79: 63-71 @ Georg Thieme

Verlag KG Stuttgart · New York | ISSN 0016-5751

Correspondence

Thomas Hildebrandt, MD, MBA

Department of Gynecology and Obstetrics,

Erlangen University Hospital

Universitätsstraße 21-23, 91054 Erlangen, Germany

thomas.hildebrandt@uk-erlangen.de

Deutsche Version unter:

https://doi.org/10.1055/a-0749-9103

\section{ABSTRACT}

Background Reduced resources for financing healthcare services are available to the German health system. For this reason, demographic development represents one of the greatest challenges for the German health system. Reproductive medicine can offer potential solutions and counteract the ageing of the population through an increase in the birth rate. Most reproductive medical treatments take place in private centres. For the development of new, innovative therapeutic approaches, continuing education and scientific advancement, university centres are essential.

Materials and Methods Using multistage contribution margin accounting, IVF and ICSI treatments at the University Fertility Centre Franken (UFF) were investigated in 2012. The cost situation from the perspective of the patient couple and the statutory payer were contrasted with the cost and revenue situation of the service provider as a university reproductive medicine centre.

Results The costs for the patient couple for an IVF treatment cycle were $538.71 €$ and for an ICSI cycle, 700.07€. For the payer, the costs, including the university flat rate $(194.80 €)$ to be paid, amount to $733.51 €$ for an IVF cycle and $894.87 €$ for an ICSI cycle. The payments of the patient couple and the payer were added and this yielded total costs of $1272.22 €$ and $1594.94 €$. The University Fertility Centre Franken, as a part of the Department of Gynaecology of the Erlangen University Hospital, incurred costs of $1364.47 €$ for an IVF treatment cycle and $1423.48 €$ for an ICSI treatment cycle. In addition, the $\mathrm{OB} / \mathrm{GYN}$ clinic had to pay the university hospital a flat general expense rate of $14.9 \%$ of the income. There was thus a loss for the department of gynaecology of $281.81 €$ for an IVF cycle and 66.19€ for an ICSI cycle.

Discussion From the perspective of a university reproductive medicine centre, IVF and ICSI treatments currently cannot be performed in a cost-covering manner. At the same time, a reproductive medicine treatment cycle represents a significant financial burden on the patient couple due to only partial cost coverage by most statutory health insurance funds. This therefore demonstrates a need for action in health policy to revise and, in the interest of the patient couples, reproductive medicine centres and, not least of all, in the interest of society, to improve existing cost absorption policies and thus also benefit from this as a society over the long term.

\section{ZUSAMMENFASSUNG}

Hintergrund Dem deutschen Gesundheitsystem stehen reduzierte Ressourcen zur Finanzierung von Gesundheitsleistungen zur Verfügung. Daher stellt die demografische Ent- 
wicklung eine der großen Herausforderungen für das deutsche Gesundheitssystem dar. Die Reproduktionsmedizin kann Lösungsmöglichkeiten bieten und der Überalterung der Gesellschaft durch eine Steigerung der Geburtenziffer entgegenwirken. Die meisten reproduktionsmedizinischen Behandlungen finden in privaten Zentren statt. Für die Entwicklung neuer innovativer Therapieansätze, die Weiterbildung und den wissenschaftlichen Fortschritt sind universitäre Zentren jedoch unerlässlich.

Material und Methoden Mithilfe einer mehrstufigen Deckungsbeitragsrechnung wurden im Jahr 2012 sowohl die IVFals auch ICSI-Behandlungen am Universitäts-Fortpflanzungszentrum Franken (UFF) untersucht. Die Kostensituation aus Sicht des Patientenpares und der gesetzlichen Kostenträger wurde der Kosten- und Erlössituation des Leistungserbringers als universitäres reproduktionsmedizinisches Zentrum gegenübergestellt.

Ergebnisse Die Kosten des Patientenpaares lagen für einen IVF-Behandlungszyklus bei $538,71 €$ und für einen ICSI-Zyklus bei 700,07€. Für den Kostenträger beliefen sich die Kosten inklusive der zu entrichtenden Hochschulpauschale (194,80€) auf $733,51 €$ für einen IVF-Zyklus bzw. 894,87€ für einen ICSI-Zyklus. Die Zahlungen des Patientenpaares und des Kos- tenträgers wurden addiert und es ergaben sich Gesamtkosten von $1272,22 €$ bzw. 1594,94€. Dem Universitäts-Fortpflanzungszentrum Franken als Bestandteil der Frauenklinik des Universitätsklinikums Erlangen entstanden Kosten von $1364,47 €$ für einen IVF-Behandlungszyklus und 1423,48€ für einen ICSI-Behandlungszyklus. Zuzüglich musste die Frauenklinik noch eine Gemeinkostenpauschale von 14,9\% der Einnahmen an das Universitätsklinikum zahlen. Es ergab sich somit ein Minus für die Frauenklinik von $281,81 €$ für einen IVF-Zyklus und von 66,19€ für einen ICSI-Zyklus.

Diskussion Aus Sicht eines universitären reproduktionsmedizinischen Zentrums sind aktuell IVF- und ICSI-Behandlungen nicht kostendeckend durchführbar. Zugleich stellt ein reproduktionsmedizinischer Behandlungszyklus aufgrund nur partieller Kostenübernahme durch die meisten gesetzlichen Krankenkassen für das Patientenpaar eine erhebliche finanzielle Belastung dar. Es wird somit ein Handlungsbedarf der Gesundheitspolitik aufgezeigt, um bestehende Kostenübernahmegrundsätze zu überarbeiten und im Sinne der Patientenpaare, reproduktionsmedizinischer Zentren und nicht zuletzt im Sinne der Gesellschaft zu verbessern und hiermit langfristig auch als Gesellschaft zu profitieren.

\section{Introduction}

Until the mid-1980s, sufficient financial resources were available in the German healthcare system. The patient, as a service recipient, received the best possible therapy and the health insurance fund covered the costs as the service reimburser [1]. However, costs in the healthcare system have continually increased in the past few decades. According to information from the Federal Office of Statistics, Germany, after the USA and Switzerland, is one of the countries with the highest healthcare spending worldwide [2]. More recent data from the Federal Office of Statistics which the Association of Research-Based Pharmaceutical Companies of Switzerland (Interpharma) publishes on its website currently demonstrate a slight change in the overall picture: Germany is now in fourth place worldwide, behind the United States, the Netherlands, and France (OECD 2014 and Federal Office of Statistics 2014 cited according to [3]). In 2010, the healthcare costs per inhabitant were $3510 €$ per inhabitant annually. In 2015, healthcare expenditures were $3829 €$ per capita [4].

Reproductive medicine represents a frequently discussed issue in the area of conflict of these allocation decisions. For a long time, there was discussion regarding the question of whether "sterility" should be considered a disease, strictly speaking. Meanwhile, this is recognised as such by the WHO. However, general and complete coverage of costs for the therapy for the disease is still lacking. Since 01 January 2004, still only $50 \%$ of the costs of an IVF or ICSI treatment is covered by statutory health insurance funds within the framework of the law on the modernisation of the German statutory health insurance funds (GMG). The cost coverage is subject to certain conditions [5]: The guidelines of the Federal Committee of Physicians and Health Insurers regard- ing medical measures for fertility treatment stipulate that a patient couple must be married. The woman must be between 25 and 40 years of age and the man must be between 25 and 50 years of age [6]. Even if the health insurance funds are free to voluntarily reimburse more than three cycles or reduce the patient couple's financial co-payment since the Healthcare Provision Act (GKV-Versorgungsstrukturgesetz) of 22 December 2011, infertile couples are exposed to financial expenses which are still high. By contrast, the willingness to cover costs for reproductive medical measures by insurers is rather low, as a work by Huppelschoten et al. shows [7]. The demographic change in Germany urgently requires solutions to solve the imbalance between young and old.

To keep the number of live births constant, there would thus need to be a significant increase in the number of births [8]. Given an increasing maternal age at first pregnancy which currently averages 29.6 years, reproductive medical centres are increasingly needed for this, along with corresponding general political conditions [9]. In Germany, 128 centres were registered in 2012 [10]. These are largely in the hands of private bodies (private individual practices and group practices, investor groups). Only 26 centres (20.3\%) are connected to or integrated with a university hospital. Medical research represents a legally stipulated and, in addition to the specialised training of young physicians, an essential activity of university hospitals. Several university hospitals no longer have their own reproductive medicine centre. The centres which still exist often have substantially fewer than 200 IVF/ICSI treatments annually, while the number in private centres extends up to 1000 punctures/year and more. Thus the question arises of whether university reproductive medical centres can break even. 
This work examines the perspective of the service providers as a university reproductive medicine centre and also the perspective of the affected patient couple in order to uncover deficits in the financing of reproductive medical measures and provide cost data for needs-based financing.

\section{Materials and Methods}

For the current work, the performance data from the University Fertility Centre Franken (UFF) which, as a part of the OB/GYN clinic of the Erlangen University Hospital, covers all areas of gynaecological endocrinology and reproductive medicine, are evaluated.

The total cost reports of the relevant cost centres, divided according to cost category, served as a basis for the present model. In addition, the number of cases and visits to the outpatient endocrinology unit in 2012 were available. Using the number of IVF and ICSI punctures provided by the biological laboratory, the number of IVF/ICSI cases in 2012 could be determined. The average number of visits of a patient per IVF and ICSI treatment was determined using a sample survey. The average costs incurred for surgery and anaesthesia for a follicular puncture and the costs of internal cost allocation and information on remuneration of staff (last updated: 1 August 2012) were determined.

\section{Determining staff costs}

To determine staff costs, interviews were held with the nurses, laboratory staff, administrative specialists and physicians of the outpatient endocrinology unit to obtain information about the individual time expenditure which results within the scope of an IVF/ICSI treatment for the respective person. The work hours of the physicians during a follicle puncture were additionally able to be determined using surgical logs.

The working time needed per IVF/ICSI treatment in minutes was subsequently multiplied with the rate per minute of the respective pay grade. The pay category 13 was specified for physicians, pay category E 6 and $\mathrm{E} 7$ for nursing staff, and pay category E 8 for laboratory staff. The staff pay is based on the public service wage agreement of the Free State of Bavaria. The total staff costs were able to be determined as follows.

\section{Definition of cost centres and cost units used}

The separable operational organisational units of a company in which costs are incurred are referred to as cost centres [11]. It had to initially be decided in which cost centres costs are incurred in the case of an IVF/ICSI treatment. In this model, the following cost centres are defined as relevant: endocrinology outpatient clinic (EO), central laboratory (CL), endocrinology laboratory (EL), biological laboratory (BL), outpatient ultrasound unit, transfusion medicine laboratory, microbiology laboratory and the OR.

An IVF and an ICSI treatment were selected as cost units in this model. The costs were distributed between the cost units using the following allocation formula:

- Total number of cases of the endocrinology outpatient unit as well as number of visits to the entire endocrinology outpatient unit (data from the division of the OB/GYN clinic of the Erlangen University Hospital),
- Table 1 Calculation model for calculating the revenues of the department of gynaecology

\begin{tabular}{|c|c|}
\hline Costs per visit & Revenue per cycle \\
\hline $\begin{array}{l}\text { Overhead costs and internal cost allocation } \\
\text { Material costs of the biological laboratory } \\
\text { Total costs for blood and laboratory testing } \\
\text { Ultrasound costs } \\
\text { Staff costs } \\
\text { InEK (Institute for the Hospital Remunera- } \\
\text { tion System) OR costs }\end{array}$ & $\begin{array}{l}\text { Payment by health } \\
\text { insurance fund } \\
\text { Payment by patient }\end{array}$ \\
\hline Sum of costs & Sum of revenue \\
\hline $\begin{array}{l}\text { Revenue } \\
\text { - Flat rate for administrative overhead costs } \\
(14.9 \%) \\
\text { - Costs }\end{array}$ & $\begin{array}{l}\text { Total revenue of } \\
\text { the OB/GYN clinic, } \\
\text { Erlangen }\end{array}$ \\
\hline
\end{tabular}

- Total number of visits by all IVF/ICSI patients (calculation using numbers of cases of the IVF/ICSI patients per IVF/ICSI cycle),

- Total number of all IVF/ICSI cases (calculation using punctures performed).

\section{Calculation}

The overhead costs of the endocrinology laboratory, the biological laboratory and the endocrinology outpatient clinic were distributed between both cost units using the above allocation formula. Likewise, an internal cost allocation of these three cost centres was performed. In the following step, a timetable for an IVF and ICSI treatment was created which comprises all examinations and measures performed per appointment, from initial presentation to follow-up consultation, within the scope of an IVF or ICSI cycle. In this way, the total costs for blood tests as well as hormone measurements by the individual laboratories, as well as ultrasound and material costs for an IVF/ICSI cycle were able to be determined. These costs were added to the costs determined by the allocation formula, the costs of the follicle puncture and the staff costs. The result represents the total expenditures within the scope of an IVF/ICSI cycle. - Table 1 presents the calculation model.

The detailed costs per IVF/ICSI treatment for the patient or the statutory health insurance fund were also determined through the division of the OB/GYN clinic. Taken together, both amounts represent the total revenue from an IVF/ICSI treatment after deduction of the flat rate for administrative overhead costs of $14.9 \%$.

In the last step, the costs of the IVF/ICSI treatment determined were subtracted from the resultant income and thus the total revenue of an IVF/ICSI treatment was calculated.

\section{Results}

\section{Calculation of the overhead costs and internal cost allocation per IVF/ICSI cycle}

In the first step, the cost types of the cost centres relevant for the IVF/ICSI treatment were determined in collaboration with the division of the OB/GYN clinic and, using allocation formulas, allocated to the IVF/ICSI treatment defined as cost units ( $\bullet$ Table 2 ). 
- Table 2 Description of the allocation formula.

\begin{tabular}{|l|c|}
\hline Allocation formula & $\begin{array}{l}\text { Value from } \\
\mathbf{2 0 1 2}\end{array}$ \\
\hline $\begin{array}{l}\text { Number of visits of the entire endocrinology out- } \\
\text { patient unit (source: Division of the OB/GYN clinic) }\end{array}$ & 7606 \\
\hline $\begin{array}{l}\text { Total number of cases of the endocrinology out- } \\
\text { patient unit (source: Division of the OB/GYN clinic) }\end{array}$ & 3496 \\
\hline $\begin{array}{l}\text { Average number of visits of an IVF/ICSI patient } \\
\text { per IVF/ICSI cycle (determination using a random } \\
\text { sample) }\end{array}$ & 8 \\
\hline $\begin{array}{l}\text { Total number of all IVF/ICSI cases (determination } \\
\text { using the punctures performed) }\end{array}$ & 141 \\
\hline
\end{tabular}

The overhead costs and costs of the internal cost allocation were distributed using the allocation formula, divided according to the individual cost centres and allocated according to the "number of visits" allocation formula. Only immunological clarifications in the case of recurrent implantation failure were allocated according to the "number of IVF/ICSI cases" since this service is performed only within the scope of ART.

The addition of all overhead costs yields $91841.00 €$ as well as a sum of the internal cost allocation of $19731.00 €$, which were allocated to the cost units. This calculation described yields an overhead cost amount of $96.60 €$ per IVF/ICSI cycle and an amount due of $30.45 €$, which had to be paid within the scope of the internal cost allocation per IVF/ICSI cycle. The overhead costs and internal cost allocation thus yield a sum of $127.05 €$ per IVF/ ICSI treatment.

\section{Timetable of an IVF/ICSI cycle}

For the further calculation, a timetable of an IVF/ICSI cycle was created with which the costs of the examinations performed during a patient visit were calculated ( $\triangleright$ Tab. 3 ). Using the comparison of random samples of the IVF/ICSI cycles, the average number of visits in each case per IVF/ICSI cycle was determined.

\section{Laboratory testing costs}

Using the lists of costs of the individual laboratories (central laboratory, endocrinology laboratory, biological laboratory, transfusion medicine laboratory, microbiological and virological institute of the Erlangen University Hospital) and taking the established IVF/ICSI treatment plan into account, total costs of $368.13 €$ for laboratory tests are calculated ( $\bullet$ Table 4 ).

\section{Ultrasound examination costs}

As can be seen from the timetable of IVF/ICSI treatments ( $\triangleright$ Tab. 3), ultrasound examinations were performed at four visits on average during an IVF/ICSI cycle. The costs of the ultrasound examinations per IVF/ICSI cycle amounted to $10.81 €$.

\section{Material costs of an IVF/ICSI cycle}

The material costs of the biological laboratory were calculated in each case for an IVF cycle and an ICSI cycle. This yields total costs for an IVF cycle without transfer of $57.89 €$, whereas the costs of an ICSI cycle without transfer are $101.68 €(\triangleright$ Table 5). The costs of the transfer of $30.67 €$ and the material costs for the creation and work-up of a semen analysis of $7.80 €$ were added to the result in each case. This therefore yields material costs of the biological laboratory totalling $96.36 €$ for an IVF cycle and total costs of $140.15 €$ for an ICSI cycle ( $\bullet$ Table 5). This calculation was based on the current material prices in each case. The material costs of the follicle puncture are not included in this calculation. These were taken into account in the InEK OR costs.

- Table 3 Treatments performed per appointment in an IVF/ICSI cycle.

\begin{tabular}{|c|c|c|c|c|c|c|c|c|}
\hline \multirow[b]{2}{*}{ Examination } & \multicolumn{8}{|c|}{ Appointments } \\
\hline & 1st & 2nd & 3rd & 4th & 5th & 6th & 7th & 8th \\
\hline Blood testing endocrinology laboratory & $\mathrm{x}$ & & $x$ & & & $x$ & & \\
\hline Differential blood count, central laboratory & & & $\mathrm{x}$ & & & & & \\
\hline Serum test, central laboratory & $\mathrm{x}$ & & $x$ & & & & & \\
\hline Coagulation status, transfusion medicine & $x$ & & $\mathrm{x}$ & & & & & \\
\hline Hormone cycle-monitoring & & $\mathrm{x}$ & $\mathrm{x}$ & & & & & \\
\hline Hormone status & $\mathrm{x}$ & & & & & & & \\
\hline Infection serology & $\mathrm{x}$ & & $\begin{array}{l}\text { xx (twice, } \\
\text { woman+man) }\end{array}$ & & & & & \\
\hline Rubella titre & $\mathrm{x}$ & & & & & & & \\
\hline Pregnancy test (serum) & & & & & & & $\mathrm{x}$ & \\
\hline Microbiology swab & $\mathrm{x}$ & & & & & & & \\
\hline Ultrasound & $\mathrm{x}$ & $x$ & $\mathrm{x}$ & & $\begin{array}{l}x(a b- \\
\text { dominal) }\end{array}$ & & & \\
\hline Telephone call & $\mathrm{x}$ & $\mathrm{x}$ & $\mathrm{x}$ & $\mathrm{x}$ & & $\mathrm{x}$ & $\mathrm{x}$ & \\
\hline
\end{tabular}


- Table 4 Laboratory testing costs.

\begin{tabular}{|l|r|r|r|}
\hline & Regular price/€ & No. per IVF/ICSI cycle & Costs per IVF/ICSI cycle \\
\hline Sum hormone status & $119.07 €$ & 1 & $119.07 €$ \\
\hline Sum hormone cycle monitoring & $37.16 €$ & 2 & $74.32 €$ \\
\hline Sum blood count EL & $2.35 €$ & 3 & $7.05 €$ \\
\hline Sum diff. blood count CL & $4.04 €$ & 1 & $4.14 €$ \\
\hline Sum serum test CL & $7.14 €$ & 2 & $14.28 €$ \\
\hline Sum coagulation & $6.68 €$ & 2 & $13.36 €$ \\
\hline Sum MIBI & $27.11 €$ & 1 & $27.11 €$ \\
\hline Sum rubella virology & $8.74 €$ & 1 & $8.74 €$ \\
\hline Sum HIV/hepatitis serology central laboratory & $24.23 €$ & 3 & $72.69 €$ \\
\hline HCG test serum & $27.37 €$ & 1 & $27.37 €$ \\
\hline Sum costs laboratory test per IVF/ICSI cycle & & & $368.13 €$ \\
\hline
\end{tabular}

\section{Costs of the follicle puncture}

The costs of the follicle puncture were determined using example cases from 2012 with the aid of an InEK calculation matrix. The calculation yields average costs of the anaesthesia of $183.44 €$ and the surgery of $305.63 €$. By adding these costs, the average expenditures of $489.07 €$ for a follicle puncture at the Erlangen $\mathrm{OB} / \mathrm{GYN}$ clinic were determined ( $\bullet$ Table 6 ).

\section{Staff costs}

The average working time of the medical staff was 134 minutes per IVF/ICSI cycle, the averaged work required on the part of the nursing staff was 185 minutes. The biological laboratory staff required an average of 175 minutes for an IVF cycle (ICSI cycle: 205 minutes). The calculation yields staff costs of $273.05 €$ for an IVF cycle and $288.27 €$ for an ICSI cycle.
- Table 5 Material costs of the biological laboratory.

\section{Material costs of the biological laboratory (BL)}

Total price incl. VAT in $€$ per IVF/ICSI cycle

\begin{tabular}{|l|r|}
\hline Sum IVF without transfer & $57.89 €$ \\
\hline Sum ICSI without transfer & $101.68 €$ \\
\hline Sum transfer & $30.67 €$ \\
\hline Semen analysis + work-up & $7.80 €$ \\
\hline $\begin{array}{l}\text { Sum laboratory material IVF including } \\
\text { transfer and semen analysis }\end{array}$ & $96.36 €$ \\
\hline $\begin{array}{l}\text { Sum laboratory material ICSI including } \\
\text { transfer and semen analysis }\end{array}$ & $140.15 €$ \\
\hline
\end{tabular}

- Table 6 Calculation of the OR and anaesthesia costs of a puncture using example cases.

\begin{tabular}{|c|c|c|c|c|c|c|}
\hline $\begin{array}{l}\text { Costs of medical } \\
\text { service in } €\end{array}$ & $\begin{array}{l}\text { Costs nursing } \\
\text { service in } €\end{array}$ & $\begin{array}{l}\text { Medications } \\
\text { in } €\end{array}$ & $\begin{array}{l}\text { Med. needs } \\
\text { in } €\end{array}$ & $\begin{array}{l}\text { Med. infra } \\
\text { in } €\end{array}$ & $\begin{array}{l}\text { Non-med. } \\
\text { infra in } €\end{array}$ & $\begin{array}{l}\text { Average costs } \\
\text { in } €\end{array}$ \\
\hline \multicolumn{7}{|l|}{$\mathrm{OR}$} \\
\hline 48.73 & 71.34 & 3.45 & 41.22 & 59.58 & 89.01 & \multirow[t]{4}{*}{305.63} \\
\hline 67.01 & 71.43 & 3.29 & 39.35 & 56.87 & 84.96 & \\
\hline 73.10 & 65.88 & 3.45 & 41.22 & 59.58 & 89.01 & \\
\hline 30.46 & 69.85 & 2.74 & 32.79 & 47.39 & 70.80 & \\
\hline \multicolumn{7}{|l|}{ Anaesthesia } \\
\hline 60.17 & 58.23 & 3.61 & 15.85 & 10.36 & 15.00 & \multirow[t]{4}{*}{183.44} \\
\hline 77.87 & 81.05 & 5.61 & 24.65 & 16.12 & 23.33 & \\
\hline 66.07 & 77.12 & 4.41 & 19.37 & 12.67 & 18.33 & \\
\hline 58.99 & 40.13 & 3.61 & 15.85 & 10.36 & 15.00 & \\
\hline
\end{tabular}




\section{Revenue of an IVF/ICSI treatment}

In a final step, all costs listed were added. The result represents the total costs of an IVF/ICSI treatment for the University Fertility Centre Franken at the OB/GYN clinic of the Erlangen University Hospital. This yields costs of $1364.47 €$ for an IVF treatment and costs of $1423.48 €$ for an ICSI treatment ( $\vee$ Table 7 ).

In the next step, these costs are contrasted with the income of the OB/GYN clinic through an IVF/ICSI cycle. The OB/GYN clinic receives $1272.22 €$ for an IVF cycle and $1594.94 €$ for an ICSI cycle from the payer and the patient couple, taken together. A flat rate for administrative overhead costs of $14.9 \%$ must be subtracted from this in each case. This therefore yields a total revenue of $1082.66 €$ for an IVF cycle and $1357.29 €$ for an ICSI cycle. Finally, the expenses of the service provider are compared to the income and this yields a loss of $281.81 €$ for an IVF cycle and $66.19 €$ for an ICSI cycle ( $\triangleright$ Table 7). In summary, it can be said that, based on the standpoint of a university fertility centre as the service provider, there is a negative contribution margin for an IVF as well as an ICSI treatment which cannot be covered by the existing remuneration.

Costs of an IVF/ICSI cycle from the perspective of the payer and patient

In general, the costs of an IVF/ICSI treatment are currently borne by health insurance funds and the patient, in equal parts. An IVF treatment results in costs of $538.71 €$ for the health insurance fund and the patient each; for an ICSI treatment, the costs are $700.07 €$. Drug costs for the stimulation which depend on the protocol selected (agonist protocol $=1262$.46 $€$; antagonist protocol $=1403.78 €$ ) and equal shares of which were borne by the patient and the payer must be added to this value. The price quotes of the medications used per cycle are taken from the 2011 "Rote Liste" (German drug directory) and were determined using the average consumption at the University Fertility Centre Franken per stimulation cycle. The long GnRHa agonist protocol and the antagonist protocol were selected for consideration since these represented the protocols used most in the University Fertility Centre Franken during the survey period. The percentage distribution of the cycles was taken from the 2012 DIR (German IVF Registry) yearbook [12], since this is comparable on a percentage basis with the distribution at the University Fertility Centre. The other protocols specified in the yearbook which did not correspond to the protocols used most were divided equally between the long GnRHa protocol and the antagonist protocol. Using the data, $57.1 \%$ of the patients were treated in the antagonist protocol, $42.9 \%$ received treatment in the long $\mathrm{GnRHa}$ agonist proto-
- Table 7 Total calculation model per IVF/and ICSI treatment of the $\mathrm{OB} / \mathrm{GYN}$ clinic of the Erlangen University Hospital.

\begin{tabular}{|l|r|r|}
\hline & \multicolumn{1}{|c|}{ IVF } & ICSI \\
\hline $\begin{array}{l}\text { Overhead costs + internal cost } \\
\text { allocation }\end{array}$ & $127.05 €$ & $127.05 €$ \\
\hline Laboratory testing & $368.13 €$ & $368.13 €$ \\
\hline Ultrasound costs & $10.81 €$ & $10.81 €$ \\
\hline Material consumption BL & $96.36 €$ & $140.15 €$ \\
\hline InEK puncture costs & $489.07 €$ & $489.07 €$ \\
\hline Staff costs & $273.05 €$ & $288.27 €$ \\
\hline $\begin{array}{l}\text { Total expenditures of the Erlangen } \\
\text { OB/GYN clinic }\end{array}$ & $1364.47 €$ & $1423.48 €$ \\
\hline $\begin{array}{l}\text { Total income of the Erlangen } \\
\text { OB/GYN clinic (pat. + payer) }\end{array}$ & $1272.22 €$ & $1594.94 €$ \\
\hline $\begin{array}{l}\text { Flat general expense rate 14.9\% } \\
\text { of the income }\end{array}$ & $189.56 €$ & $237.65 €$ \\
\hline $\begin{array}{l}\text { Revenue: } \\
\text { Income } \\
\text { - Flat general expense rate } \\
\text { - Expenses, OB/GYN clinic }\end{array}$ & $-281.81 €$ & $-66.19 €$ \\
\hline
\end{tabular}

col. The average stimulation costs of an IVF cycle of $1343.28 €$ for payer and patient together and average stimulation costs of an ICSI cycle of $1340.65 €$ were able to be calculated using these data. This yields costs for the patient and health insurance fund in each case of $671.64 €$ for an IVF stimulation treatment and costs of $670.33 €$ for an ICSI stimulation treatment.

Moreover, for the payer, there is still a university flat fee of $194.80 €$ to be paid ( $97.40 €$ each for woman/man) per IVF/ICSI cycle. In summary, there are total costs of $1405.15 €$ incurred for the payer for an IVF treatment and total costs of $1562.20 €$ for an ICSI treatment ( $>$ Table 8 ).

For the patient, the total costs amount to $1210.35 €$ for an IVF treatment and $1370.40 €$ for an ICSI treatment ( $\vee$ Table 8).

\section{Discussion}

The results of the calculation make it clear that under the existing remuneration, an IVF/ICSI treatment cannot be performed without losses for a university fertility centre. Currently, the department can only be sustained through cross-subsidisation from other areas.

- Table 8 Overview of costs of an IVF/ICSI cycle from the perspective of the patient/payer.

\begin{tabular}{|l|r|r|r|r|}
\hline & \multicolumn{1}{|l|}{ IVF } & Payer & ICSI & Patient \\
\hline Treatment costs & Patient & $538.71 €$ & $733.51 €$ & $700.07 €$ \\
\hline Drug costs & $671.64 €$ & $671.64 €$ & $1405.15 €$ & $670.33 €$ \\
\hline Sum of costs & $1210.35 €$ & $670.33 €$ & $1370.40 €$ \\
\hline
\end{tabular}


However, to achieve further advancements in the treatment of sterility and infertility, it is essential for research and science to offer corresponding treatments in a university setting. There must be a suitable infrastructure to derive hypotheses and, in the next step, implement them in practice [13]. Notably, the first IVF baby also came into existence in a university setting. Further innovations will be possible only within a suitable university setting since private practices generally do not have a suitable infrastructure to promote corresponding research activities. In addition, training and continuing education take place within university structures in particular. This must remain guaranteed over the long term. At present, continuing education in gynaecological endocrinology and reproductive medicine cannot be sufficiently ensured by outpatient structures. Under the premise that this model calculation can also be applied to other university centres, the continued existence of the entire field in Germany would be jeopardised. It is therefore essential to adequately remunerate fertility treatment at a university hospital to continue to ensure a corresponding research environment [14].

In the field of fertility protection as well, the preservation of university fertility centres is essential: the first successful ovarian transplantation following chemotherapy by the University of $\mathrm{Er}$ langen OB/GYN clinic in 2008 and the first pregnancy following a successful ovarian transplantation through cooperation between the centres of the Bonn, Dresden and Erlangen university hospitals in 2011 demonstrate the importance of university centres in reproductive medicine [15]. Close collaboration between the various medical disciplines, especially oncology and reproductive medicine, is of great importance for the success of a treatment $[13,16]$. This infrastructure can largely only be offered at university centres. In contrast to this is the decreasing number of endocrinology, reproductive medicine and andrology departments at the universities and the growing market share of private reproductive medicine practices in which up to $75 \%$ of artificial fertilisations are currently performed. At present, the cooperation between practices and university hospitals is not sufficient [13]. Clear concepts and networks would have to be created to ensure the successful continued existence of reproductive medicine in Germany $[17,18]$. In addition, the infrastructure of the university centres must be adequately remunerated. This requires sufficient financing which should not be shifted to the patients or service providers [13]. Otherwise Germany can no longer compete internationally with other countries in the field of reproductive medicine in terms of science and also with regard to aspects of treatment quality. This development is fostered by both the relatively restrictive legal situation and on the other hand by the inadequate remuneration [13].

One possibility for achieving coverage of the costs of the IVF/ ICSI cycle would be to adequately remunerate all of the care up to the follicle puncture. The accounting standard could be adapted and the number of points per EBM (physicians' fee scale) number could be increased with proof of defined criteria. Cost coverage for university centres could be achieved through this measure.

On the part of the OB/GYN clinic, the two largest cost elements which are incurred during an IVF/ICSI treatment are, on the one hand, the costs of the follicle puncture (489.07 $€$ ) and the costs of the laboratory testing $(368.13 €)$. The costs for the follicle puncture appear high at first, however upon closer inspection, they can be fully explained; the follicle puncture takes place in the main OR of the $\mathrm{OB} / \mathrm{GYN}$ clinic of the Erlangen University Hospital. Consequently, the entire medical and non-medical infrastructure must be shared. In addition, of the total costs of the follicle puncture, $188.44 €$ is proportionately due for the anaesthesia. These costs are explained by the fact that not only the working time of the anaesthesia team must be paid, but that the infrastructure must be proportionately financed in turn. This also includes, for example, the background anaesthesia services. One option for saving costs would therefore be the outsourcing of the follicle puncture to an external outpatient OR. These considerations are only theoretical possibilities, since in a university centre, the hiring of external anaesthesia services is not expedient for the entire clinic. In addition, high investment costs would be needed to create a separate centre for reproductive medicine and find suitable facilities for the follicle puncture. In the case of the current investment backlog by the federal states, this plan would not be feasible in the foreseeable future.

Another possibility for increasing the clinic's revenue would be to also offer more individual healthcare services (IHCS) in university facilities, which would result in greater competition with the private-practice physicians. This could subsequently result in fewer referrals and it remains doubtful whether the number of IVF/ICSI treatments would increase in university facilities over the long term through this measure.

Private reproductive medicine centres have various competitive advantages. These include in particular the acquisition of external services (e.g. anaesthesia) on the free market with corresponding competitive pressure of the providers. On-call and other services which are shifted from the main OR of a university centre to the individual ORs do not apply here. In addition, there is the possibility of offering extensive individual healthcare services (IHCS) in a private setting. Here as well, limits are placed on a university centre such that the economic result is negatively influenced, in comparison to private providers.

With regard to the limitations of the model, it must be noted that these involve calculations which are based on the infrastructure and conditions at the OB/GYN clinic of the Erlangen University Hospital. The results yielded cannot be arbitrarily transferred to every reproductive medicine facility and instead used and interpreted only taking the respective infrastructure into consideration. In other centres, there may be deviations due to structural conditions.

In view of the enormous economic gain for German society through each additional child who participates in the gross national product in later life, the existing subsidies should be critically reconsidered by the health policy and self-evident decisions should be made using the data which are now available. Affected couples are greatly burdened by the current deductible of $50 \%$ and complete cost coverage and adequate payment of the centres appear necessary from a social perspective [19]. This model clearly shows that even if the general public, in this case in the form of the statutory health insurance fund, financed $100 \%$ of an IVF/ICSI cycle, society would greatly benefit from this regulation over the long term. Society would experience this, for example, in the form of new taxpayers and the health insurance funds 
would benefit from this through the increase in new members. In addition, Domar et al. were able to show in particular that a high financial burden, in addition to psychological factors, represents a main reason for discontinuing IVF treatment [20]. In addition, the German state must reflect on the role which Germany wishes to continue to play in international reproductive medicine: The position of German policy with regard to newer techniques and the resultant value of egg donation or surrogacy must be reconsidered. The embryo protection law of 1992 has numerous gaps and urgently needs to be revised to be able to address the new developments over the past 20 years. Only in this way will physicians, patient couples and also the health insurance funds once again have a firm basis on which they can orient themselves. In light of the many new developments in the field of reproductive medicine which also arise from an ethical as well as a medical perspective, it must be considered whether, in Germany, a national authority similar to the Human Fertilisation and Embryology Authority (HEFA) in Great Britain should be created. There, HEFA has, among others, the task of ensuring compliance with the highest medical standards in the case of fertility treatments performed. It also addresses ethical questions, monitoring, approval and compliance regarding embryo research and advises the public with regard to questions on treatment reports [21]. Similar approaches have been taken in the USA by the American Fertility Society [22]. Since this authority exclusively deals with reproductive medicine, it can react promptly to new developments and clarify new issues. These clear guidelines provide a solid legal basis under which decisions by the patient couple and the treatment team can be made.

\section{Conclusion}

Under the current general conditions, cost-covering treatment of infertile couples by means of IVF/ICSI treatments at university reproductive medicine centres, as was shown at the University Fertility Centre Franken, for example, is not feasible. However, the majority of the training of young reproductive medicine physicians takes place at such institutions. And also research projects are generally possible only through the prevailing infrastructure at these centres. In addition, the treatments also continue to represent a high financial burden for the affected couple. Within the scope of the work, possible solutions for appropriate remuneration were able to be shown. Thus it is now the task of politics to recognise the potential of reproductive medicine measures, particularly also from the perspective of society and implement corresponding measures for cost-covering remuneration for the service providers in order to not jeopardise the future of reproductive medicine in Germany through insufficient training and a lack of scientific infrastructure.

\section{Conflict of Interest}

The authors declare that they have no conflict of interest.

\section{References}

[1] Lux MP, Beckmann MW. Klinische Ökonomie in der gynäkologischen Onkologie. FHA 2008; 2: 35-41

[2] Gesundheitsberichterstattung des Bundes. Gesundheitsausgaben im internationalen Vergleich Kapitel 5.4 [Gesundheit in Deutschland, 2006], 2006. Online: http://www.gbe-bund.de/gbe10/abrechnung.prc_abr_ test_logon?p_uid=gastg\&p_aid=\&p_knoten=FID\&p_sprache=D\&p_ suchstring=10918: Gesundheitsausgabe; last access: 20.07.2017

[3] Interpharma. Höhere Gesundheitsausgaben in den Industriestaaten. Interpharma 2015. Online: http://www.interpharma.ch/fakten-statistiken /1873-hoehere-gesundheitsausgaben-industriestaaten; last access: 20.07.2017

[4] Robert Koch-Institut. Gesundheitsberichterstattung des Bundes. Gemeinsam getragen von RKI und Destatis. Gesundheit in Deutschland. Berlin: Robert Koch-Institut; 2015

[5] Kentenich H, Sibold C, Tandler-Schneider A. [In vitro fertilization and intracytoplasmic sperm injection: Current medical aspects]. Bundesgesundheitsbl Gesundheitsforsch Gesundheitsschutz 2013; 56: 16531661

[6] Richtlinien des Bundesauschusses der Ärzte und Krankenkassen über ärztliche Maßnahmen zur künstliche Befruchtung („Richtlinien über künstliche Befruchtung“), in der Fassung vom 14. August 1990 - veröffentlicht im Bundesarbeitsblatt 1990, Nr.12 zuletzt geändert am 16. März 2017, veröffentlicht im Bundesanzeiger BAnz AT 01.06.2017 B4, in Kraft getreten am 2. Juni 2017. Online: https://www.g-ba.de/ downloads/62-492-1402/KB-RL_2017-03-16_iK-2017-06-02.pdf; last access: 17.10.2018

[7] Huppelschoten AG, Verkerk EW, Appleby J et al. The monetary value of patient-centred care: results from a discrete choice experiment in Dutch fertility care. Hum Reprod 2014; 29: 1712-1720

[8] Statistisches Bundesamt. Geburtenzahl durch demografische Entwicklung vorgezeichnet. 2013. Online: https://www.destatis.de/ bevoelkerungspyramide/\#!y $=1960 \& v=2 \& 0=2060 v 1$; last access: 01.08.2017

[9] Craig BM, Donovan KA, Fraenkel L et al. A generation of childless women: lessons from the United States. Womens Health Issues 2014; 24 : e21-e27

[10] Bühler K. D.I.R Annual 2012 of the German National IVF Registry. J Reprod Med Endocrinol 2013; 10: 1-47

[11] Graumann M, Schmidt-Graumann A. Rechnungslegung und Finanzierung der Krankenhäuser, Leitfaden für die Rechnungslegung und Finanzierung der Krankenhäuser, Leitfaden für Rechnungslegung, Beratung und Prüfung, Alle Teilbereiche des Rechnungswesens der Krankenhäuser, Integrierende Darstellung juristischer und betriebswirtschaftlicher Aspekte, Mit zahlreichen Fallbeispielen und Abbildungen. Hamm: Neue Wirtschafts-Briefe GmbH \& Co. KG; 2007

[12] [Anonym]. Deutsches IVF Register-Jahrbuch 2012. J Reproduktionsmed Endokrinol 2013; 10: 1-47

[13] Lux MP, Fasching PA, Loehberg CR et al. Health Services Research and Health Economy - Quality Care Training in Gynaecology, with Focus On Gynaecological Oncology. Geburtsh Frauenheilk 2011; 71: 1046-1055

[14] Gleicher N, Kushnir VA, Barad DH. Why Prospectively Randomized Clinical Trials Have Been Rare in Reproductive Medicine and Will Remain So? Reprod Sci 2016; 23: 6-10

[15] Frauenklinik des Universitätsklinikum Erlangen. Erstmals Kind trotz Unfruchtbarkeit nach Brustkrebstherapie - Eierstockgewebe retransplantiert. 2012. Online: http://www.frauenklinik.uk-erlangen.de/aktuelles/ nachrichten/detail/rstmals-kind-trotz-unfruchtbarkeit-nachbrustkrebstherapie-eierstockgewebe-retransplantiert/; last access: 30.10 .2016 
[16] Dittrich R, Kliesch S, Schuring A et al. Fertility Preservation for Patients with Malignant Disease. Guideline of the DGGG, DGU and DGRM (S2 kLevel, AWMF Registry No. 015/082, November 2017) - Recommendations and Statements for Girls and Women. Geburtsh Frauenheilk 2018; 78: 567-584

[17] Guenther V, Alkatout I, Junkers W et al. Fertility Preservation in Female Patients with Breast Cancer - a Current Overview. Geburtsh Frauenheilk 2017; 77: 1088-1094

[18] Stachs A, Hartmann S, Gerber B. Preservation of Fertility or Ovarian Function in Patients with Breast Cancer or Gynecologic and Internal Malignancies. Geburtsh Frauenheilk 2017; 77: 861-869

[19] Campbell M, Sahin-Hodoglugil NN, Potts M. Barriers to fertility regulation: a review of the literature. Stud Fam Plann 2006; 37: 87-98
[20] Domar AD, Rooney K, Hacker MR et al. Burden of care is the primary reason why insured women terminate in vitro fertilization treatment. Fertil Steril 2018; 109: 1121-1126

[21] Kooperation international. HFEA Human Fertilisation and Embryology Authority. 2015. Online: http://www.kooperation-international.de/ detail/info/hfea-human-fertilisation-and-embryology-authority.html; last access: 15.08.2017

[22] Kolata G. In vitro fertilization goes commercial. There could be as many as 200 clinics operating within a year; who should pay for the procedures, and how should they be monitored? Science 1983; 221: 11601161 